\title{
CASARSE EN LATÍN. DETERMINACIÓN DE LA DIÁTESIS LÉXICA MATRIMONIAL
}

This paper tries to establish the relations between two intertwined aspects of the complex world of Roman marriage: the social aspect and the linguistic one. The Roman marriage appears to be based on an interplay of relations between the bride's father, the bride and the bridegroom, all of them depending on one economical element: the dowry. The different verbal lexemes used in Latin show the different types of marriage and the point of view they are looked upon from.

0. El matrimonio romano ha sido objeto de multitud de estudios sobre su significado social en un entorno jerárquico y familiar como es el romano y, desde luego, como antecedente de nuestro propio rito religioso ${ }^{1}$. También existe algún estudio, escasos, sobre el léxico empleado para la expresión de la unión matrimonial en todas sus fases, desde los esponsales hasta la boda propiamente dicha ${ }^{2}$. En este sentido, el presente trabajo se ciñe a la significación léxica y la repercusión social que suponen el léxico empleado, la estructura sintáctica acuñada y el número de participantes.

En este análisis se va a utilizar como instrumento básico el concepto clasemático de la diátesis léxica y gramatical ${ }^{3}$; las relaciones entre los actantes de las acciones verbales en conexión es fundamental para entender el significado social del matrimonio en Roma, ya que la interrelación entre léxico y sociedad aparece muy acentuada en una parcela de carácter familiar como es éste.

1 Cf. sobre este tema, El matrimonio en Occidente, de J. Gaudemet, Madrid, 1993.

2 Un trabajo detallado al respecto es el de «Semántica y sociología: análisis lexemático del matrimonio romano», de A. Ma Martín Rodríguez, Estudios Humanísticos 9, Universidad de León, 1987, pp. 179-204. Siempre será útil, por otro lado, la consulta del manual Le Vocabulaire des Institutions Indoeuropeénnes I-II, de E. Benveniste, Paris, 1969.

3 Para una determinación inequívoca del concepto de diátesis léxica, véase B. García Hernández, Semántica estructural y lexemática del verbo, Reus, 1980. 
La diátesis léxica, a diferencia de la diátesis gramatical, fija su perspectiva en el número de personajes implicados en una acción verbal inicial. Así, una frase como pater pecuniam filio dat desencadena la presencia por diátesis de la frase pecunia filio est, que, a su vez, supone la frase filius pecuniam habet. Por tanto, entre los lexemas verbales do / sum / habeo existe una relación diatética léxica que se expresa del modo siguiente: do . - sum . -habeo, es decir, la relación diatética es una relación secuencial intersubjetiva como consecuencia del cambio de sujetos.

\section{Generalidades. Determinación de los actantes.}

Si aplicamos el análisis diatético a los lexemas verbales que habitualmente aparecen en contextos matrimoniales, la relación descrita no puede ser más que uir ducit . - uxor nubit. Esta afirmación, sin ser falsa, es parcial por el hecho de que el matrimonio es un acto que trasciende la voluntad de los novios y va más allá de su deseo de contraer matrimonio. En efecto, el primer paso que hay que dar para entender el funcionamiento del matrimonio romano es la consideración de la figura paterna de ambos cónyuges como desencadenante real del acto matrimonial; aunque en principio se puede considerar que en todo el ámbito amoroso, incluido el matrimonio, los protagonistas son dos actantes, sin embargo, tal distinción corresponde a nuestro conocimiento de la realidad, pero no al análisis de los datos de lengua. Sin duda, la figura del padre es la más representativa, pero no la única, puesto que la madre, el hermano o un tío pueden desempeñar por igual la función de contratar el matrimonio. Así es, las nupcias romanas no pasan de ser un contrato entre tutores con un intercambio económico. Pero todos estos detalles se van a examinar a continuación, una vez aclarado el número y carácter de los protagonistas del acto: el padre, el joven y la doncella.

El análisis léxico de un acto cultural supone la enumeración y distinción de los diversos lexemas verbales que sirven para la expresión de una misma realidad. En este aspecto, la consideración de la sinonimia como fenómeno presente en todas las relaciones léxicas se hace necesaria. La sinonimia ${ }^{4}$ existe en cuanto que un grupo de palabras tienen el mismo referente real y, por ello, están cruzados por una serie de rasgos significativos mínimos que los pone en relación; ahora bien, los sinónimos siempre presentan matices o grados que,

4 Creemos, como Adrados, que en la sinonimia hay que considerar como factores de diferencia las connotaciones «o matices no intelectuales que se les han adherido a los sinónimos de su uso en determinados niveles del lenguaje: familiar, infantil, técnico, poético, etc.», en Lingüística estructural I, Madrid, $1980^{2}$, p. 542. 
en ocasiones, afectan a factores alejados del significado ${ }^{5}$. Pues bien, la determinación de esos rasgos distintivos, que dan pie a los matices y pueden modificar su funcionamiento, supone la ruptura de la denominada sinonimia completa ${ }^{6}$. Y para la determinación del significado del acto de casarse en latín hay que tener en cuenta las diferencias de matiz de los distintos lexemas verbales.

\section{Lexemas verbales del ámbito matrimonial.}

La lengua latina está provista de varios lexemas verbales para expresiones parecidas, que se reparten entre los actantes que participan en la acción. En el análisis de los lexemas se va a empezar por los protagonizados por el padre, puesto que es el desencadente de todo un proceso social y léxico.

- Lexemas verbales de la figura del padre.

Por orden de frecuencia ${ }^{7}$, los lexemas propios del padre son (de)spondeo, do y (col)loco, junto a lexías formadas sobre estos lexemas verbales, a saber, do nuptum, colloco nuptum. Es fácil deducir que el análisis que se extraiga de las bases léxicas ha de transferirse a las lexías correspondientes. Son los textos los que determinan las diferencias entre los lexemas; la primera distinción se establece entre do y spondeo:

$\mathrm{CH}$ (pater): Si illa tibi placet, placendo dos quoque est quam dat tibi.

Postremo quod uis non duces, nisi illud quod non uis feres.

CA: Ius hic orat. LY (adulescens): Impetrabit te aduocato atque arbitro.

Istac lege filiam tuam spondem mi uxorem dari?

CH: Spondeo. CA: Et ego spondeo idem hoc (Tri. 1159-63).

La lectura diferencial del texto es de carácter aspectual; es decir, la acción de spondeo indica que el proceso matrimonial está en marcha, pero puede interrumpirse. La promesa, pues, que lleva implícita el lexema spondeo no supone la realización del acto de la entrega matrimonial que supone do filiam, sino que dicha promesa puede incumplirse, en tanto que la acción de do filiam implica su cumplimiento:

AL: Di me perdant -ME: Quodcumque optes, tibi uelim contingere.

AL: Sei illam uxorem duxero umquam, mihi quam despondit pater!

5 Nos referimos, en particular, a la llamada arquitectura, concepto desarrollado por E. Coseriu en Principios de semántica estructural, Madrid, $1986^{2}$, pp. 13-4.

6 Defendida a ultranza por G. Salvador en Semántica y lexicología del español, Madrid, 1985, pp. 51-66.

7 Todos los datos y ejemplos de este trabajo están extraídos de las obras de Plauto y Terencio. 
ME: Et me, si umquam tibi uxorem filiam dedero meam

(Ci. 497-9).

Esta explicación tiene su plasmación en una estructura léxica sencilla basada en el aspecto no resultativo - - resultativo que define a los lexemas:

No resultativo - - Resultativo

pater spondet - - dat filiam

Con todo, las relaciones aspectuales no se implican mutuamente, lo que supone la posibilidad de no aparecer en el proceso: (spondeo) - - (do). Además de la relación aspectual que los diferencia, entre ambos lexemas verbales existe otro rasgo de uso que los condiciona notablemente, en especial, al lexema no resultativo. Se trata de la especificación del agente de la acción, de modo que spondeo necesita o condiciona que su agente sea la figura paterna frente a $d o$, que admite cualquier variante: madre, hermano, tío, etc.:

CH: Filiam meam tibi desponsatam esse audio. LY: Nisi tu neuis.

CH: Immo hau nolo. LY: Sponden ergo tuam filiam uxorem mihi?

$\mathrm{CH}$ : Spondeo et mille auri Philippum dotis. LY: Dotem nil moror (Tri.1156-8).

Este dato posibilita la relación proporcional entre los tres agentes matrimoniales y sus respectivos lexemas verbales:

$$
\frac{\text { uir }}{\text { duco }}:: \frac{\text { uxor }}{\text { nubo }}:: \frac{\text { pater }}{\text { spondeo }}
$$

La presencia de la dote va necesariamente unida a este tipo de lexemas verbales, puesto que un matrimonio socialmente aceptado supone la entrega al novio de la prometida y de la cantidad en la que el padre fija el valor de su hija, dinero que va a resultar decisivo en las relaciones personales dentro del matrimonio; tan es así que la uxor dotata se convierte en una personaje tipificado en la comedia plautina ${ }^{8}$ como la matrona de mal carácter que tiene sometido al marido ${ }^{9}$; por tanto, la presencia de la dote no es un dato marginal, sino decisivo en la valoración social y personal de la mujer dentro del matrimonio.

El tercer lexema verbal que se emplea para la descripción de este ámbito matrimonial es colloco, que no parece tener relación alguna con los otros dos lexemas verbales. El lexema colloco, a tenor de los datos, muestra un llamativo cambio en la perspectiva del padre con respecto a la boda de su hija y ello tiene consecuencias directas sobre el proceso matrimonial desarrollado por los novios. Los ejemplos demuestran que la intención inicial de casar a la hija parte del padre y que, por tanto, no existe una petición previa por parte del novio o representante de éste. En efecto, los lexemas spondeo y do responden a una situación previa que parte de un tercero, bien por enamoramiento, bien por violación, bien por necesidad; el caso es que las condiciones se negocian directamente entre preten-

8 La tipificación de este personaje ha sido realizada por E.Schuhmann en «Der Typ der uxor dotata in den Komödien des Plautus», en Philologus 21, 1977, pp. 45-65.

9 Reproduzco, a modo de ejemplo, estos textos: - Nam quae indotata est, ea in potestate uiri est (Aul. 533); Argentum accepi, dote imperium uendidi (As. 87). 
diente y padre, quedando relegada la figura de la hija a un papel marginal. Esta perspectiva condiciona el tipo de diátesis léxica que se configura en torno a los lexemas spondeo y do (lexemas causativos), en la que la relación padre-novio motiva el desarrollo de la acción:

pater spondet filiam . -

. - adulescens uxorem ducit . -

. - uirgo adulescenti nubit

Con respecto a colloco, igualmente causativo, las motivaciones del padre son muy distintas y el deseo primero de casar a su hija parte de él, como se ha anticipado. Este hecho modifica sensiblemente la estructura formal del desarrollo matrimonial, y la relación más estrecha se configura sobre el padre y la hija, quedando relegado, en este caso, el papel del novio como figura accidental que entra en el proceso matrimonial para dar respuesta a una necesidad compartida por padre e hija. Por ello, la diátesis se ve afectada en el orden de los actantes:

pater filiam collocat. -

. - filia nubit alicui . -

. - aliquis filiam ducit

Naturalmente, este proceso implica unas connotaciones de tipo social que permiten establecer notables diferencias entre las dos formas de casarse que conforma la lengua latina, condicionadas por la postura paterna. Los datos apuntan a que si la iniciativa del casamiento parte del padre, se delata que la situación económica de éste no es lo suficientemente buena para hacer frente a una petición matrimonial al uso. Ello supone la búsqueda de un marido que acepte sin dote o con dote escasa a una joven, que sacrificará su condición social para liberar al padre de la obligación de dotarla:

SO: Ego autem, quae essem anus deserta, egens ignota,

ut potui nuptum uirginem locaui huic adulescenti (Ph. 751-2).

Sobre todo hay que subrayar que, junto a la lectura social que supone el tipo de lexema verbal empleado para la figura del padre, el orden de la secuencia complementaria entre los novios se ve alterada, de resultas del mayor o menor grado de relación que se establece entre la acción paterna y el receptor de dicha acción; en efecto, con la presencia de spondeo o do, la acción repercute directamente sobre el pretendiente y ello provoca la secuencia más documentada en los textos y que mejor define le matrimonio romano, sustentada, eso sí, en la presencia de la dote:

$\mathrm{CH}$ : Si illa (filia) tibi placet, placenda dos quoque est quam dat tibi.

Postremo quod uis non duces, nisi illud quod nos uis feres.

CA: Ius hic orat. LY: Impetrabit te aduocato atque arbitro.

Istac lege filiam tuam spondem mi uxorem dari?

CH: Spondeo (Tri. 1159-63).

En este texto confluyen todos los elementos necesarios para una boda socialmente acomodada, incluso los elementos escénicos, es decir, la conversación entre padre y pretendiente; por tanto, la secuencia que se construye emplea el orden y los lexemas implicados:

pater filiam spondet - - dat . - adulescens uxorem ducit 
Sin embargo, con el empleo de colloco, la acción recae sin paliativos sobre la hija, lo que provoca la articulación lingüística de una estructura secuencial menos documentada, porque se trata de una boda sin dote:

pater collocat . - filia nubit alicui . - aliquis ducit

En este caso, los datos son escasos y resulta difícil encontrar la secuencia completa; ahora bien, no hay que olvidar que el lexema verbal causativo provoca, habitualmente, la presencia de un lexema verbal no causativo; en el caso de los lexemas matrimoniales de la figura paterna, los lexemas no causativos que la lengua articula, bien sean spondeo - - do, bien sea colloco, son dos: duco . - nubo por un lado, y nubo . - duco por otro. Con este dato se pretende significar que hay lexemas no causativos más obligados que otros, de manera que el verdadero lexema no causativo obligado de spondeo/do resulta ser duco, y el lexema no causativo real de colloco resulta ser nubo. Esta aclaración tiene dos repercusiones: que los lexemas no causativos duco/nubo son complementarios equivalentes entre sí, en dependencia de la variante diatética en la que se vean inmersos; y que los textos tienden a ejemplificar la estructura binaria más congruente, sin que por ello deje de aparecer, en las condiciones adecuadas, una estructura ternaria (cf. Tri. 1159-63) o una estructura binaria menos congruente (lexema verbal causativo seguido de lexema verbal no causativo facultativo):

SE: At satius fuerat eam uiro dare nuptum potius. LE: Heia!

Haec quidem ecastor cottidie uiro nubit, nupsitque hodie

(Ci. 42-3).

Este texto documenta la secuencia menos congruente do nuptum filiam - filia nubit, lo que viene a demostrar que el proceso secuencial está sujeto al arbitrio del autor y finalmente es él el que elige los lexemas que quiere realzar; pero, en todo caso, los lexemas elegidos pertenecerán a una de las dos variantes diatéticas matrimoniales determinadas.

\section{- Lexemas verbales de la figura del novio.}

El lexema verbal propio es el ya tratado $d u c o$, cuyo orden de aparición se ve motivado por la presencia del lexema verbal del que es agente la figura del padre. Por tanto, no se va a insistir más en la secuencia diatética y se van a analizar los otros lexemas verbales del novio, sin perder de vista que, al tratarse de modificados de duco, están sujetos a las mismas motivaciones que el lexema base.

Son dos, en concreto, los lexemas verbales articulados para expresar la conducción de la novia de la casa del padre a la del novio, pero condicionados por un cambio de perspectiva u orientación, que se basa en un juego preverbial; se trata de los lexemas abduco y deduco que, designando la misma realidad, el cambio de domicilio de la novia, expresan significados distintos.

El lexema abduco significa el traslado de la novia desde el punto de vista del padre y, por ello, la combinación sintagmática insiste referencialmente en el antiguo domicilio:

Ceterum uxorem quam primum potest abduce ex aedibus

(Tru. 847). 
Mientras, deduco significa la conducción de la novia a la casa del novio ${ }^{10}$, es decir, la referencia se centra, en este caso, en el nuevo domicilio:

PA: Vt pauca redeam, uxorem deducit domum.

Nocte illa prima uirginem non attigit (Hc. 135-6).

No es extraño que la lengua articule dos lexemas verbales basados en la óptica de las dos figuras que, de hecho, dirigen la acción matrimonial, en las dos personas que lingüísticamente se pueden sentir afectadas por el proceso, el padre y el novio, en tanto que la valoración de la novia no es que quede relegada, es que no es considerada. Esta ausencia en forma verbal constituye también un dato de la consideración casi nula en que es tenido el papel de la mujer en el proceso matrimonial, hecho que coincide con la minoría de edad de la mujer a efectos jurídicos en la sociedad romana.

Dicho esto, quisiera profundizar algo más en la diferencia de uso de ambos lexemas, puesto que es por todos conocido que la deductio constituye "la ceremonia más significativa desde el punto de vista de los usos sociales" ${ }^{11}$. No hay que olvidar que el objetivo básico del acto matrimonial consiste en la creación de un marco de tradición que asegura una vida común, es decir, la creación de la familia; y dentro de la familia, el elemento característico es la procreación, de ahí que lo realmente significativo de la boda sea la orientación hacia el futuro que la deductio implica.

\section{—Lexemas verbales de la figura de la novia.}

Como en el caso anterior, la lengua articula un lexema propio para la expresión del matrimonio por parte de la mujer: nubo. Funciona, como se ha dicho, como complementario no causativo de la diátesis léxica matrimonial y está sujeto, al igual que duco, al lexema verbal de la figura paterna.

Ya se ha analizado su papel en el primer punto y, a diferencia de duco no presenta modificados verbales. Sin embargo la lengua utiliza otros lexemas verbales para la expresión matrimonial de la mujer, si bien con verbos de movimiento, es decir, intransitivos: eo nuptum (matrimonium) / uenio domum. Este dato coincide con la intransitividad del lexema nubo, que se construye con un dativo destinatario, a diferencia del resto de los lexemas matrimoniales, bien del padre, bien del novio, que son, sin excepción, transitivos.

10 Puede resultar importante la precisión léxica que sobre el preverbio de-realiza B.García Hernández en «NOMINA RELATIVA (termes complémentaires) dans les grammairiens latins», Colloque International Conceptions latines du sens et de la signification (en prensa): «Il est probable que les expressions deducere coloniam et deducere nouam nuptam font voir le même sens de descente observé dans l'emploi ci-dessus de copias ... deducit. S'il est ainsi, il faudra envisager la fondation d'une colonie comme l'action de 'faire descendre' quelques habitants de la métropole dans une nouvelle ville et la cérémonie du mariage comme l'action de 'faire descendre' l'épouse de la maison de pater familias au domicile conjugal» (p. 35).

11 Cf. M. I. Núñez Paz en Consentimiento matrimonial y divorcio en Roma, Salamanca, 1988, p. 68. 
En primer lugar hay que reconocer que la productividad de todos los lexemas verbales femeninos de este ámbito es escasa y, aún más, la de las lexías eo nuptum / uenio domum. Estas lexías deben ser explicadas en dos sentidos: por un lado, la diferencia significativa que opera entre ellas; por otro, cómo y dónde se insertan en el proceso matrimonial.

Con respecto al primer problema, la solución radica en la perspectiva del desarrollo de la acción; como ya ocurría con los lexemas verbales propios del novio abduco y deduco, existen dos ópticas para la contemplación del mismo hecho: la dirección desde la casa paterna (it nuptum), la dirección a la casa del esposo (uenit domum). Por tanto, el mismo eje funcional de la parcela significativa del novio, es aplicable a la de la novia, de manera que la dirección orientada con respecto a las dos figuras masculinas del proceso nupcial se revela distintiva.

La segunda cuestión resulta ser de otra índole; debe ser analizada dentro de la diátesis léxica detectada y explicada en el punto primero, pero, además, debe ser relacionada con la secuencias intrasubjetivas de cada agente analizado. En efecto, al dilucidar la diferencia aspectual entre spondeo y do se estableció que formaban parte del mismo proceso como término no resultativo y resultativo respectivamente:

spondeo filiam - - do filiam

Idéntico análisis cabe realizar con los lexemas del ámbito del novio, que forman, pues, un proceso aspectual:

abduco/deduco uxorem - - duco uxorem

Por último, y siguiendo con la misma estructura, los lexemas verbales de la novia parcecen estar sujetos a similar proceso aspectual:

eo nuptum/uenio domum - - nubo

Este desdoblamiento aspectual que afecta a los tres procesos intrasubjetivos de una diátesis intersubjetiva, multiplica ostensiblemente el número de combinaciones que puede articular la lengua al describir el acto matrimonial, sin que por ello quede afectada la estructura ternaria del proceso:

ME: Vt quidem emoriar priu' quam ducam.

Sed his legibu' si quam dare uis, ducam:

quae cras ueniat, perendie, soror, foras feratur (Au. 154-6).

Este texto representa la diátesis léxica matrimonial de una boda dotada: soror dat . - uir ducit . - uirgo uenit (domum). Pero hay otros textos que recogen la variante léxica de la boda mal dotada:

CA: Namque hercle honeste fieri ferme non potest, ut eam perpetiar ire matrimonium

sine dote, quom eius rem penes me habeam domi.

MA: Parata dos domist nisi exspectare uis,

ut eam sine dote frater nuptum conlocet (Tri. 731-5).

En este caso, la ausencia de dote obliga al hermano a concertar un matrimonio indigno, en el que se omite, precisamente, el lexema verbal de la acción del novio, es decir, la presencia menos relevante en esta unión: frater nuptum collocat . soror it matrimonium . - [uir ducit]. 


\section{Conclusiones.}

Del presente trabajo pueden extraerse las siguientes conclusiones:

- La diátesis léxica existente entre los verbos para la expresión del matrimonio romano refleja claramente la realidad social de éste.

- La ausencia o presencia de la dote en las uniones nupciales condiciona el empleo de lexemas verbales distintos para un enlace con dote (spondeo) y otro sin dote (colloco). El primero presupone la relación directa entre el padre y el novio y da lugar a la secuencia spondeo . - duco . -nubo. El segundo, por su parte, presupone la relación directa entra padre e hija: colloco . - nubo . - duco.

-Algunos lexemas verbales, con identidad referencial y también de sujeto, se diferencian en función de criterios aspectuales (aspecto no resultativo - resultativo) y del criterio de la dirección orientada (casa del padre o del novio como referencia espacial).

Teniendo en cuenta estas coordenadas de carácter lexemático, no resulta tan difícil comprender el contenido social que rezuman los textos y, por tanto, la realidad social que se esconde tras ellos.

ROSARIO LÓPEZ GREGORIS 